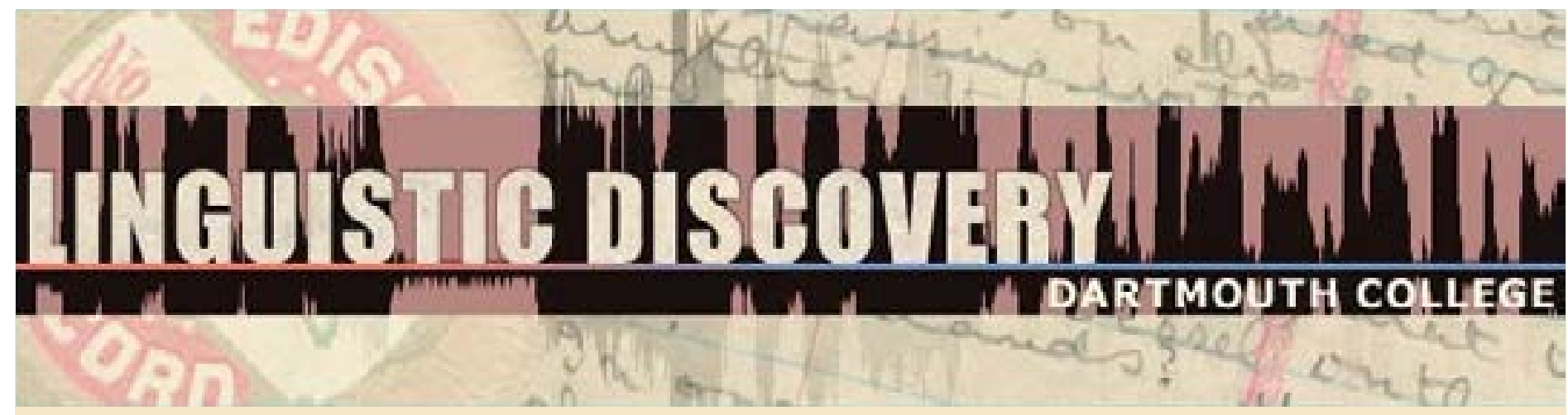

Volume 4 Issue 1 2006
Idiosyncratic Factors in Language Endangerment: The Case of Upper Sorbian

Bernard Comrie

Max Planck Institute for Evolutionary Anthropology and University of California Santa Barbara

Paulina Jaenecke

Alpha Sprachstudio, Zürich

doi: 10.1349/PS1.1537-0852.A.302

url: http://journals.dartmouth.edu/cgi-bin/WebObjects/ Journals.woa/1/xmlpage/1/article/302
Linguistic Discovery

Published by the Dartmouth College Library Copyright to this article is held by the authors. ISSN 1537-0852 linguistic-discovery.dartmouth.edu 


\title{
Idiosyncratic Factors in Language Endangerment: The Case of Upper Sorbian
}

\author{
Bernard Comrie \\ Max Planck Institute for Evolutionary Anthropology and University of California Santa Barbara
}

Paulina Jaenecke

Alpha Sprachstudio, Zürich

The Sorbian-speaking area represents a minority Slavic enclave within the eastern part of Germany, around the towns of Bautzen (Budysin) and Cottbus (Chosebuz). The area divides naturally and linguistically into two sub-areas, Upper Lusatia (around Bautzen) and Lower Lusatia (around Cottbus), with two corresponding standard written languages, Upper Sorbian and Lower Sorbian. The separation of the wo varieties is reinforced by th

Language retention in different parts of the Sorbian-speaking area is markedly different. For Low rer sobian, Jodkaure al. (2001:39) reckon win an upper is markedy to exceed 7000 speakers, on the basis of a survey carried out in 1993-5, well down from that the overwhelming majority of traditional speakers are aged over 60. Šatava (2005:17) notes that Upper Sorbian has about 20-25000 speakers, less than half of whom, however. use the language actively on a daily basis. But within Upper Sorbian, there is a substantial difference between the vitality of Sorbian in Protestant and Catholic communities. In the Catholic communities, located in the triangle Bautzen - Hoyerswerda - Kamenz, 60-65\% of the population is able to speak Sorbian, in some sub-areas $80-90 \%$; there is even a probability of around $40 \%$ (in the sub-areas, $60 \%$ ) that a randomly chosen pair of inhabitants will speak Sorbian with one another.

In earlier work, the difference between language vitality of Upper and Lower Sorbian has often been attributed to differences between the linguistic policies of the political entities that preceded German unification in 1871 and to some extent followed until 1918, Upper Sorbian being spoken in more laissez-faire Saxony, Lower Sorbian in more centralist incidentally, speakers of Lower Sorbian are traditionally Protestant.

More generally, we feel that it is important to pay attention to individual factors, often very local and idiosyncratic, that can play a role in fostering or diminishing the vitality of a threatened or potentially threatened language. This does not imply a denial of the importance of establishing general principles in this area, only that any particular case is likely to involve an interaction between general principles and more idiosyncratic factors. Religion in the Sorbian-speaking area is one such factor.

First, Catholic religion provides a distinguishing feature between Catholic speakers of Upper Sorbian and almost all their neighbors, including German-speakers, reinforced by traditional dispreference for marriage across the Catholic-Protestant divide. Saxony has since the Reformation been a bastion of Protestantism (even if it did have a Catholic royal family from 1697 to 1918). There has been no such barrier separating Protestant speakers of Upper or Lower Sorbian. from their Cerman-speaking neighbors. It is perhaps significant that one of Cerlation's in
Easter Riding in the Catholic Sorbian Communities

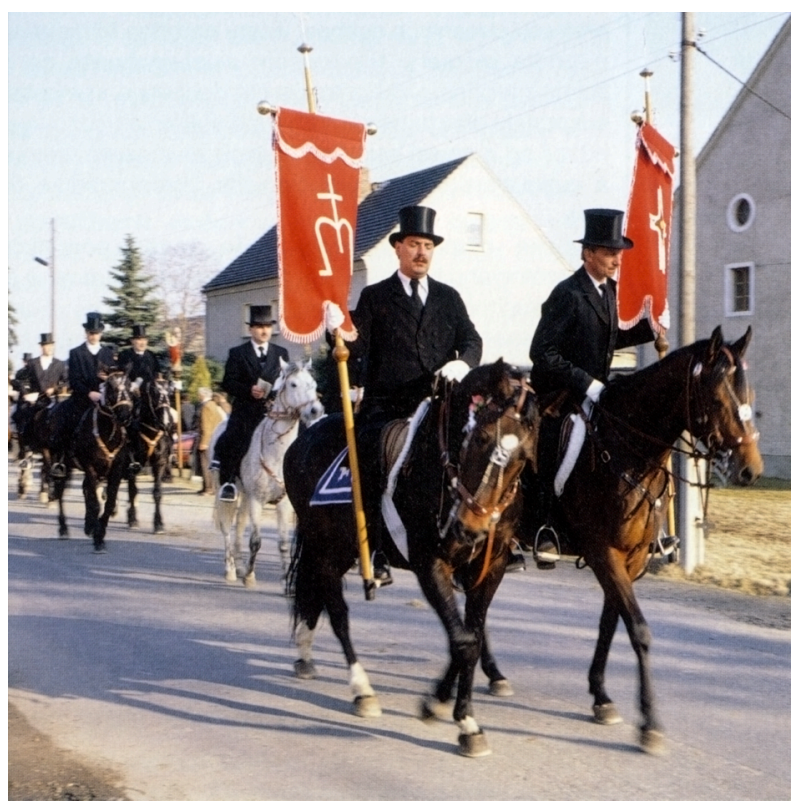

Sorbian-Speaking Area: Historical Overview Since 1789 (Jaenecke 2003: 43)

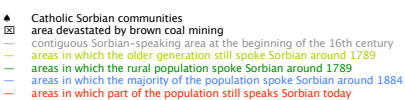

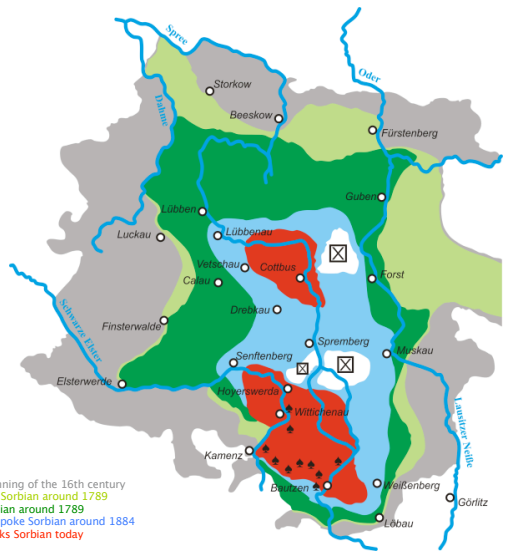

Second, there has developed a close link between aspects of Upper Sorbian Catholicism and the use of the Sorbian language, as documented in detail by Jaenecke (2003: 374). Upin solure and Catholic religion is embodied in anticle 10 of the the between the Holy See and the Free State of Saxony from 1996, enacted in Saxon state law in 1997 (Sächsisches Gesetz- und Verordnungsblatt 1997.3: 18): "The Catholic Church will

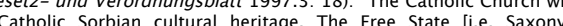
supports the Catholic Church in this within the bounds of its possibilities." There is no corresponding agreement with the Lutheran-Evangelical Church, either for Upper or Lowe Sorbian.

Quite generally, knowledge of Sorbian is expected, by priests and members of the congregation alike, as a necessary condition on participation in religious activities Jaenecke 2003: 374). One striking illustration of this close link between religion an culture among the Upper Sorbian-speaking Catholics is the tradition of "Easter riding" riding is defined as a Uatholic Sorbian custom and is indeed one 2003 . 232-242). Easter traditional culture among the Catholic Sorbs. The active participants are men aged 14 or above, who must also be able to participate actively in the accompanying singing in Sorbian. Even during the National Socialist period, when public use of Sorbian was in general prohibited, Easter riding with public use of Sorbian was used as a sign of Catholic Sorbian identity under the limited protection that the Catholic Church was able to offer its parishioners against state power.

The importance of the link between Catholic religion and Sorbian identity was recognized by the National Socialist government, which tried to counter this link by forcing the reassignment of Sorbian-speaking clergy to non-Sorbian-speaking parishes and vice the Cerman Dem, thatic Republic led in some cases to alienation between lavinuage and religion among Protestant Sorbs, as seen in the comment of an inhabitant of the Lower Sorbian-speaking village of Dissen (Jodlbauer et al. 2001: 178): "The Church was a concern of the Wends [= Sorbs], but after 1945 only unbelieving Wends were supported by the state. Only the atheists among the Sorbs, not the religious ones, were fostered." Among Catholic Sorbs, the link between religion and language remained more salient than that

between language policy and the state.
Developments since reunification, however, pose threats to the factors that have fostered language vitality in the Catholic Sorbian-speaking area. First, reunification, coupled with contemporary geographical mobility, means that the marriage pool as define by religion is much greater - in Germany as a whole, Catholics and Protestants are about marrying a Sorbian-speaker are no longer effectively limited to a choice among Sorbianspeakers. Second, and perhaps even more important, there are currently no Sorbianspeakers in Catholic seminaries, i.e. after the retirement of the current generation of Catholic clergy there are unlikely to be Sorbian-speaking clergy capable of communicating with their parishioners in Sorbian.

References

Jaenecke, Paulina. 2003 Religiosität und Spracherhalt bei den katholischen Sorben. Berlin

Weißensee Verlag.
Jodlbauer, Ralph, Gunter Spieß, Han Steenwijk. 2001. Die aktuelle Situation der niedersorbischen Sprache. Bautzen: Domowina-Verlag.

Šatava, Leoš. 2005. Sprachverhalten und ethnische Identität. Bautzen: Domowina-Verlag. Creville 1993 . Corbet. London/New York: Routledge, 593-685. 